\title{
Potential dermal wound healing agent in Blechnum orientale Linn
}

\author{
How Yee Lai ${ }^{1}$ Yau Yan Lim² ${ }^{2 *}$ and Kah Hwi Kim³
}

\begin{abstract}
Background: Blechnum orientale Linn. (Blechnaceae) is used ethnomedicinally to treat wounds, boils, blisters or abscesses and sores, stomach pain and urinary bladder complaints. The aim of the study was to validate the ethnotherapeutic claim and to evaluate the effects of $B$. orientale water extract on wound healing activity.

Methods: Water extract of B. orientale was used. Excision wound healing activity was examined on SpragueDawley rats, dressed with $1 \%$ and $2 \%$ of the water extract. Control groups were dressed with the base cream (vehicle group, negative control) and 10\% povidone-iodine (positive control) respectively. Healing was assessed based on contraction of wound size, mean epithelisation time, hydroxyproline content and histopathological examinations. Statistical analyses were performed using one way ANOVA followed by Tukey HSD test.

Results: Wound healing study revealed significant reduction in wound size and mean epithelisation time, and higher collagen synthesis in the $2 \%$ extract-treated group compared to the vehicle group. These findings were supported by histolopathological examinations of healed wound sections which showed greater tissue regeneration, more fibroblasts and angiogenesis in the $2 \%$ extract-treated group.

Conclusions: The ethnotherapeutic use of this fern is validated. The water extract of B. orientale is a potential candidate for the treatment of dermal wounds. Synergistic effects of both strong antioxidant and antibacterial activities in the extract are deduced to have accelerated the wound repair at the proliferative phase of the healing process.
\end{abstract}

\section{Background}

Blechnum orientale Linn. (Blechnaceae) is a perennial terrestrial fern natively distributed in Malaysia and is commonly known as the Centipede fern or 'paku ikan' (by the Malays) or 'dungau' (by natives in Sabah) or 'Kuan Chung' (by the Chinese). It is used ethnomedicinally to treat wounds, boils, blisters or abscesses and sores [1], for stomach pain, urinary bladder complaints $[2,3]$ and sterilization of women [4]. Young fronds are boiled and eaten as vegetable by the natives $[5,6]$. As its ethnotherapeutic use in wound treatment has not been scientifically researched and in view of the strong bactericidal and antioxidant activities of the water extract as reported in our previous studies $[7,8]$, an in vivo investigation was undertaken to evaluate the potential of the extract for treatment of wounds.

\footnotetext{
* Correspondence: lim.yau.yan@sci.monash.edu.my

${ }^{2}$ School of Science, Monash University Sunway Campus, Bandar Sunway, 46150 Petaling Jaya, Selangor, Malaysia Full list of author information is available at the end of the article
}

Wound healing is currently a clinical challenge due to inconsistencies encountered in the healing processes. Medical treatment includes administration of drugs either locally (topical) or systemically (oral or parenteral) with the aim to either shorten the time required for healing or to minimize the undesired consequences during wound repair [9]. Medicinal plants have generated much interest for treatment of skin ailments as they are affordable and purportedly safe from hypersensitive reactions [10].

Wound is defined as a breaking of cellular and anatomical or functional continuity of living tissue [11]. There are three phases in the process of wound healing. Phase 1 is the coagulation and inflammatory phase that involves migration of neutrophils at the margin of incision. Phase 2 is the proliferative phase which is characterized by angiogenesis, collagen deposition, epithelization and wound contraction. Angiogenesis involves new blood vessel growth from endothelial cells. Granulation tissue progressively invades the incision
C Biomed Central 
space. Collagen fibrils become more abundant and begin to bridge the incision. At this phase, the epithelization depends on the migratory, proliferative and differential abilities of keratinocytes and these are regulated by growth factors such as epidermal growth factor family and fibroblast growth factor family $[12,13]$. Phase 3 is a remodeling phase involving continuous accumulation of collagen and proliferation of fibroblasts. This phase involves synthesis of collagen fibers, leading to increase in tensile strength of the skin [14]. Alterations in any of these steps can lead to healing delay or even the inability to heal completely [15].

Our earlier studies $[7,8]$ have revealed the presence of tannins in the water extract. This extract was also found to possess strong antioxidant and antibacterial activities. The radical scavenging activity of the water extract was found to be equivalent to the reference $\alpha$-tocopherol with $\mathrm{IC}_{50} 13.0 \pm 1.3 \mu \mathrm{g} / \mathrm{mL}$ [7]. The water extract also recorded good bactericidal activities against five Grampositive bacteria including methicillin-resistant Staphylococcus aureus MRSA (minimum bactericidal concentration MBC $62.5 \mu \mathrm{g} / \mathrm{mL}$ ) [7]. Subsequently, we undertake this study to support our hypothesis that both antioxidant and antibacterial activities in the water extract could play a synergistic role in the treatment of wounds and also to validate scientifically its ethnotherapeutic role in skin diseases. To the best of our knowledge, this is the first report on the efficacy of $B$. orientale on wound healing.

\section{Methods}

\section{Plant material and extraction}

Blechnum orientale Linn. was obtained from Putrajaya Botanical Garden, Kuala Lumpur. The identity was confirmed by plant taxonomist Anthonysamy S., formerly from University Putra Malaysia and currently a consultant with the landscape consulting firm, Aroma Tropic Limited, Kuala Lumpur. A voucher specimen (LAA007) was deposited at the Herbarium of Monash University Sunway Campus.

The extracts were prepared as previously described [7]. Briefly, powdered leaves of $B$. orientale were extracted with methanol at room temperature. The extract solution was filtered and the solvent was evaporated under reduced pressure. After freeze-dried, the dark green mass obtained (17\% yield based on dry leaves) was suspended in distilled water $(1: 10, \mathrm{w} / \mathrm{v})$ and partitioned successively with petroleum ether $40-60^{\circ} \mathrm{C}$, chloroform, ethyl acetate and $n$-butanol. In the final partitioning with butanol, the lower water layer was removed and concentrated under reduced pressure. It was then freeze-dried to obtain a dry brown powder mass labelled as the water extract $(6.5 \%$ yield based on dry leaves). The sample was stored at $-70^{\circ} \mathrm{C}$ until used.

\section{Quantitation of total tannins}

Total tannins were determined as previously described [16]. Tannins were distinguished from nontannins by using polyvinylpolypyrrolidone (PVPP) which has a high affinity for tannins. Total phenolics content (TPC) was measured using the Folin-Ciocalteau method [7] before and after treatment with PVPP. Treatment with PVPP was conducted as follows. Distilled water $(1 \mathrm{~mL})$ was added to PVPP (100 mg) before adding $1 \mathrm{~mL}$ extract. The mixture was vortexed and centrifuged at $3000 \mathrm{~g}$ for 10 min. Supernatant was collected and TPC was determined as before. The standard curve was prepared using $2-10 \mu \mathrm{g} / \mathrm{mL}$ tannic acid. Tannin content was calculated as the difference between total phenolics (before PVPP treatment) and the nontannin phenolics (after PVPP treatment). Results were expressed as grams tannic acid equivalent (TAE) per $100 \mathrm{~g}$ dry weight.

\section{Animals model}

This study was approved by the University Ethics Committee of the Monash University for animal experimentation (SOBSB/MY/2009/46). Sprague-Dawley rats (200 - $250 \mathrm{~g}$ ) of either sex were purchased from the Animal House of Monash University Sunway campus. Each animal was caged individually and acclimatized for 7 days, under a climate-controlled environment $\left(22.0 \pm 3^{\circ} \mathrm{C}\right)$ and relative humidity $30-70 \%), 12$-h dark and light cycles. Standard rodent chow pellets were given ad libitum with free access to water.

\section{Materials}

Aqueous cream (manufactured by Pharmaniaga Manufacturing Bhd, Malaysia) and povidone-iodine 10\% solution (manufactured by Polylab Sdn. Bhd, Malaysia) were purchased from a local pharmacy store. 4dimethylaminobenzaldehyde and chloramines $\mathrm{T}$ were purchased from Acros, citric acid and sodium citrate from Fischer and hydroxyproline from Sigma. All other chemicals were of extra-pure grade and used as received.

Two concentrations of the water extract cream was formulated using aqueous cream base as the vehicle. The aqueous cream consisted of emulsifying wax (9\%), white soft paraffin (15\%), liquid paraffin (6\%), chlorocresol $(0.1 \%)$, glycerin $(5 \%)$ and purified water. For $1 \%(\mathrm{w} /$ w) extract cream, $1 \mathrm{~g}$ of the dry water extract was incorporated in $100 \mathrm{~g}$ of aqueous cream and warmed at 50$55^{\circ} \mathrm{C}$, with constant stirring until a homogeneous extract-cream formation was obtained. For $2 \%(\mathrm{w} / \mathrm{w})$ extract cream, $2 \mathrm{~g}$ of the dry water extract was used in place of $1 \mathrm{~g}$ of the extract. The extract cream was weighed into eppendorf tubes (approximaely $0.20 \mathrm{~g}$ per tube) and left to equilibriate at room temperature for 3 days, before use. 


\section{Wound healing activity}

The procedure described by Nayak et al. (2009) [13] was followed with slight modifications. The animals were divided into four groups with six animals per group. Animals were anaesthetized by intraperitoneal injection of ketamine/xylazine (ketamine at $100 \mathrm{mg} / \mathrm{kg}$ and xylazine $10 \mathrm{mg} / \mathrm{kg})$. An area $\left(150 \mathrm{~mm}^{2}\right)$ was marked using a frame and marker pen. The required area (approximately $5 \mathrm{~mm}$ bigger than the marked area) of the dorsal fur of the animals was shaved with an electric clipper. The area was sterilized by spraying with $70 \%$ ethanol. A full thickness skin $\left(150 \mathrm{~mm}^{2}\right)$ was excised from the predetermined area by removing the epidermis and dermis layer until the subcutaneous fat (avoiding panniculus carnosus and the muscle layer). Carprofen at $5 \mathrm{mg} / \mathrm{kg}$ was injected subcutaneously every day for 5 days as analgesia.

Group I was applied topically with aqueous cream (negative control), group II with povidone-iodine 10\% (Polylab ${ }^{\circledR}$, positive control), groups III and IV with $1 \%$ and $2 \%(\mathrm{w} / \mathrm{w})$ water extract cream respectively. The reference (povidone-iodine), extract cream and the base cream were applied topically (dose approximately 0.20 g/wound) once a day until the wound was completely healed or to a maximum of 14 days. Special care was taken to avoid variation in the dose given.

Animals were monitored every day. An animal monitoring sheet was used to record all observations e.g. its activity, alertness, body condition, body weight, breathing, its coat condition, signs of dehydration, drinking, eating, conditions of its eyes, feces, nose, urine, its movement and vocalization.

The wound area contractions were measured on the $1^{\text {st }}$ (wounding day) and thereafter every alternate day until completely healed. The wound margin was traced on a sterile autoclaved transparent paper (3 times to get an average area) and then placed on a graph paper to determine the area. Wound contraction was calculated as percentage reduction of initial wound area. Wounds were considered closed (completely healed) if moist granulation tissue was no longer apparent and the wound was covered with new epithelium.

After complete healing, rats were killed using carbon dioxide gas [17]. The healed skin was excised. A small piece of tissue was fixed in $10 \%$ formalin for histopathological examination. The remaining tissue was used for the determination of total collagen in the hydroxyproline assay.

\section{Determination of total collagen - Hydroxyproline assay}

The procedure used for the hydrolysis of the granulation tissue is as described by Nayak et al. (2009) [13]. The wet weight of the granulation tissue was recorded. The tissue was dried at $60^{\circ} \mathrm{C}$ for $12 \mathrm{~h}$ and the dry tissue weight recorded. To the dried tissue, $5 \mathrm{~mL} 6 \mathrm{~N} \mathrm{HCl}$ was added and autoclaved at $120^{\circ} \mathrm{C}$ for $20 \mathrm{~min}$. The neutralized acid hydrolysate of the dry tissue was used for the hydroxyproline assay.

Total collagen was determined following the method described by Jorge et al. (2008) [14]. Hydrolyzed samples $(20 \mu \mathrm{L})$ were added to 96 -well plate and incubated for $20 \mathrm{~min}$ at room temperature with $50 \mu \mathrm{L} /$ well of chloramines $\mathrm{T}$ solution (282 $\mathrm{mg}$ chloramines $\mathrm{T}, 2 \mathrm{~mL}$ $n$-propanol, $2 \mathrm{~mL}$ distilled water, and $16 \mathrm{~mL}$ citrate acetate buffer). Then $50 \mu \mathrm{L} /$ well of Erlich's solution $(2.5$ g 4-dimethylamino benzaldehyde, $9.3 \mathrm{~mL} n$-propanol, and $3.9 \mathrm{~mL} 70 \%$ perchloric acid) was added and incubated for $15 \mathrm{~min}$ at $65^{\circ} \mathrm{C}$. Absorbance was measured at $550 \mathrm{~nm}$ with a microplate reader. Hydroxyproline concentrations from 0 to $20 \mu \mathrm{g} / \mathrm{mL}$ were used to make a standard curve. Results were expressed as mg of hydroxyproline per $g$ of dry tissue.

\section{Histopathological studies}

Skin specimens were immediately fixed in $10 \%(\mathrm{v} / \mathrm{v})$ neutral-buffered formalin with the fixative solution replaced every 2 days until the tissues hardened. Each specimen was embedded in a paraffin block and thin sections $(3 \mu \mathrm{m})$ were prepared and stained with Masson trichrome (for detection of collagen fibers) and haematoxylin and eosin (H\&E) (for general morphological observations). Slides were examined qualitatively under a light microscope, for collagen formation, fibroblast proliferation, angiogenesis, epithelization and granulation tissue formation, employing light to intense scale (+ to +++$)[15,18]$.

\section{Statistical analysis}

All data were expressed as mean \pm SD. Statistical analyses were evaluated by one-way ANOVA followed by Tukey HSD test. Values with $\mathrm{P}<0.001$ were considered statistically significant.

\section{Results}

Previous studies [7] have shown that the water extract of $B$. orientale consisted of tannins and possessed strong $\mathrm{DPPH}$ radical scavenging $\left(\mathrm{IC}_{50} 13.0 \pm 1.3 \mu \mathrm{g} / \mathrm{mL}\right)$ and antibacterial activities (minimum inhibitory concentrations towards MRSA, MSSA, M. luteus, B. cereus and S. epidermidis were $31.3-62.5 \mu \mathrm{g} / \mathrm{mL}$ ) (Table 1 ). In this study, total tannins in the water extract were found to be $20 \pm 4 \%$ (g tannic acid equivalent/100 g extract).

\section{Wound contraction and days of epithelization}

Results of the wound contraction and days of epithelization are shown in Table 2. The 2\% extract-treated group demonstrated significantly higher wound contracting ability $(\mathrm{P}<0.001)$ than the vehicle group. The wound 
Table 1 Antioxidant and antibacterial activities of water extract of B. orientale [7]

\begin{tabular}{lcr}
\hline & Water extract of $\boldsymbol{B}$. orientale & Reference used \\
\hline DPPH radical scavenging activity $\left(I C_{50}, \mu \mathrm{g} / \mathrm{mL}\right)$ & $13.0 \pm 1.3$ & $12.0 \pm 0.7$ \\
& & $(\boldsymbol{\alpha}$-Tocopherol) \\
\hline Antibacterial activities & MRSA 62.5 & 1.9 (Vancomycin) \\
(Minimum inhibitory concentration $\mathrm{MIC}, \mu \mathrm{g} / \mathrm{mL})$ & MSSA 62.5 & 1.9 (Vancomycin) \\
& M. luteus 31.3 & 1.9 (Vancomycomycin) \\
& B. cereus 62.5 & 1.9 (Vancomycin) \\
\hline
\end{tabular}

Abbreviation: DPPH, 1,1-diphenyl-2-picrylhydrazyl. Microorganisms: MRSA, methicillin-resistant Staphylococcus aureus ATCC33591; MSSA, methicillin-susceptible Staphylococcus aureus ATCC25923; M. luteus, Micrococcus luteus ATCC4698; B. cereus, Bacillus cereus ATCC14579; S. epidermidis, Stapylococcus epidermidis ATCC12228.

area of the $2 \%$ extract-treated group, as measured on every alternate day, showed significant contraction from $20 \%$ on day 2 , to $62 \%$ on day $6,93 \%$ on day 10 (Figure 1D) and was completely healed on day 14 . In comparison, vehicle group showed only $4 \%$ contraction on day $2,41 \%$ on day $6,73 \%$ on day 10 (Figure $1 \mathrm{~A}$ ) and $85 \%$ on day 14 (Table 2). It is of interest to note that similar contractions were seen in both $1 \%$ extract-treated and povidoneiodine groups e.g. on day 2 (16-18\%), day 4 (28-30\%), day 8 (75-77\%), day 10 (81-85\%), day $12(90-93 \%)$ and day 14 (95-97\%) (Table 2). Overall, the contraction of wound was in the order of $2 \%$ extract-treated $>1 \%$ extract-treated $\approx$ povidone-iodine-treated $>$ vehicle.

Epithelization time refers to the number of days taken by the wounds to appear completely closed with no moist granulation tissue and the wound was covered with new epithelium. Wounds dressed with $2 \%$ extract were found to epithelize the fastest (13.0 days), followed by povidone-iodine group (16.6 days) $\approx 1 \%$ extract group (17.6 days) while the vehicle group took an average of 19.2 days to completely heal (Table 2). Nevertheless, there were no significant differences in the mean epitheliziton time among wounds dressed with 1\% extract, vehicle and povidone-iodine. This indicated the healing potential of the extracts was dose dependent and was effective only at a $2 \%$ concentration of the extract.

\section{Collagen synthesis}

Hydroxyproline is an amino acid essential for collagen synthesis. For this reason, hydroxyproline content has been used as a marker to determine the collagen content [19]. Estimation of hydroxyproline content revealed significantly higher hydroxyproline content in the $2 \%$ extract-treated animals, povidone-iodine control group and the normal (unwounded) skin compared to that of the vehicle (Figure 2). Nevertheless, there were no significant differences in the level of hydroxyproline when the animals were treated with $1 \%$ or $2 \%$ of the extract.

\section{Histopathological study}

Histopathological examinations of the healed wounds are shown in Figures 3 and 4. Two types of stains were used: Masson-trichrome (MT) for collagen deposition and hematoxylin \& eosin (H\&E) for general morphology. Masson-trichrome stains collagen blue, while cytoplasm, red blood cells and muscle are stained red, and is typically used to assess the advancement of collagen deposition during the formation of granulation tissue and matrix remodeling [20]. The blue colour staining intensity corresponds to the relative quantity of collagen fiber deposit, which reflects the process of synthesis and degradation and remodeling as well as the timing of the lesion [21]. H\&E stains collagen fibers pale pink, cytoplasm purple, nuclei blue and red blood cells cherry red.

Table 2 Effect of extracts on wound contraction and days of epithelization

\begin{tabular}{ccccc}
\hline Day & Vehicle & \multicolumn{2}{c}{ Wound area $\left(\mathbf{m m}^{\mathbf{2}}\right) \pm$ S.D. (\% contraction) } & 2\% extract \\
\hline 0 & $169.8 \pm 13.8$ & Povidone-iodine & 1\% extract & $160.2 \pm 17.8$ \\
2 & $163.7 \pm 10.4(4 \%)$ & $133.7 \pm 12.0(18 \%)$ & $139.7 \pm 15.4(16 \%)$ & $128.7 \pm 13.4(20 \%)^{*}$ \\
4 & $132.6 \pm 11.9(22 \%)$ & $116.0 \pm 10.9(28 \%)$ & $115.8 \pm 7.1(30 \%)$ & $101.0 \pm 10.7(37 \%)^{*}$ \\
6 & $100.0 \pm 18.7(41 \%)$ & $92.0 \pm 12.2(44 \%)$ & $71.0 \pm 6.7(57 \%)$ & $60.5 \pm 4.7(62 \%)^{*}$ \\
8 & $54.3 \pm 9.8(67 \%)$ & $40.8 \pm 8.3(75 \%)$ & $38.1 \pm 1.8(77 \%)$ & $25.6 \pm 1.8(84 \%)^{*}$ \\
10 & $45.8 \pm 5.5(73 \%)$ & $30.8 \pm 7.5(81 \%)$ & $25.5 \pm 2.0(85 \%)$ & $13.0 \pm 1.5(93 \%)^{*}$ \\
12 & $32.0 \pm 5.9(81 \%)$ & $11.5 \pm 5.9(93 \%)$ & $16.5 \pm 2.9(90 \%)$ & $4.9 \pm 0.6(97 \%)^{*}$ \\
14 & $25.5 \pm 6.4(85 \%)$ & $5.0 \pm 0.9(97 \%)$ & $8.8 \pm 0.9(95 \%)$ & $0.8 \pm 0.9(100 \%)^{*}$ \\
\hline
\end{tabular}

Days of epithelization

$19.2 \pm 1.5$

$16.6 \pm 1.0$

$17.6 \pm 0.9$

$13.0 \pm 0.4^{*}$

Results are as mean \pm S.D. for 6 rats per group. Percentages of contraction are recorded in parentheses. ${ }^{*}$ implies significant difference at $\mathrm{P}<0.001$ compared to the vehicle group. 

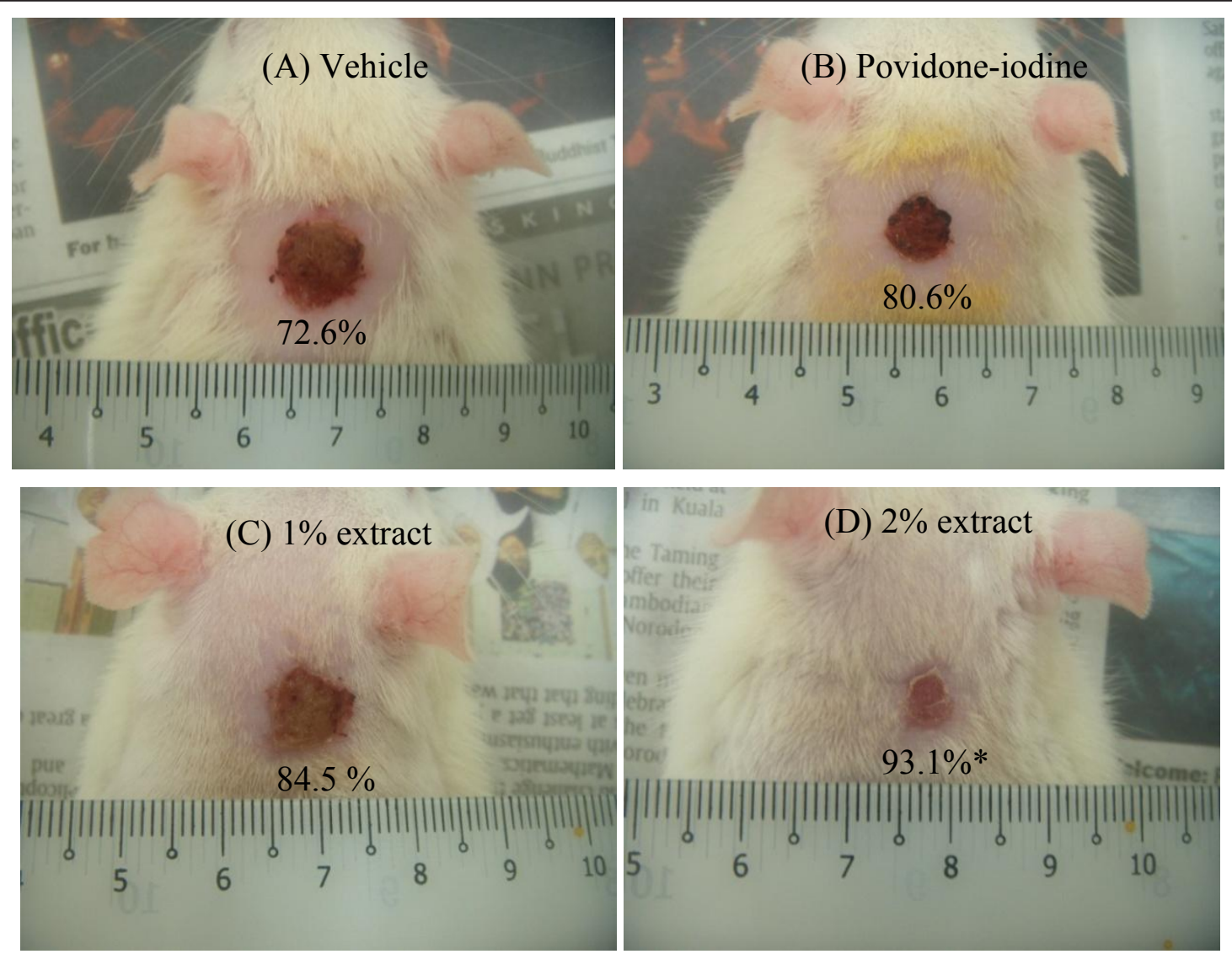

Figure 1 Appearance of wounds at Day 10 post wounding. A = vehicle group, B = povidone-iodine treated group, C = 1\% extract-treated group, $D=2 \%$ extract-treated group. Values are mean \pm S.D. for 6 rats, showing $\%$ contraction of wound size on Day $10 .{ }^{*}$ implies significant difference $(P<0.001)$ in comparison with the vehicle group.

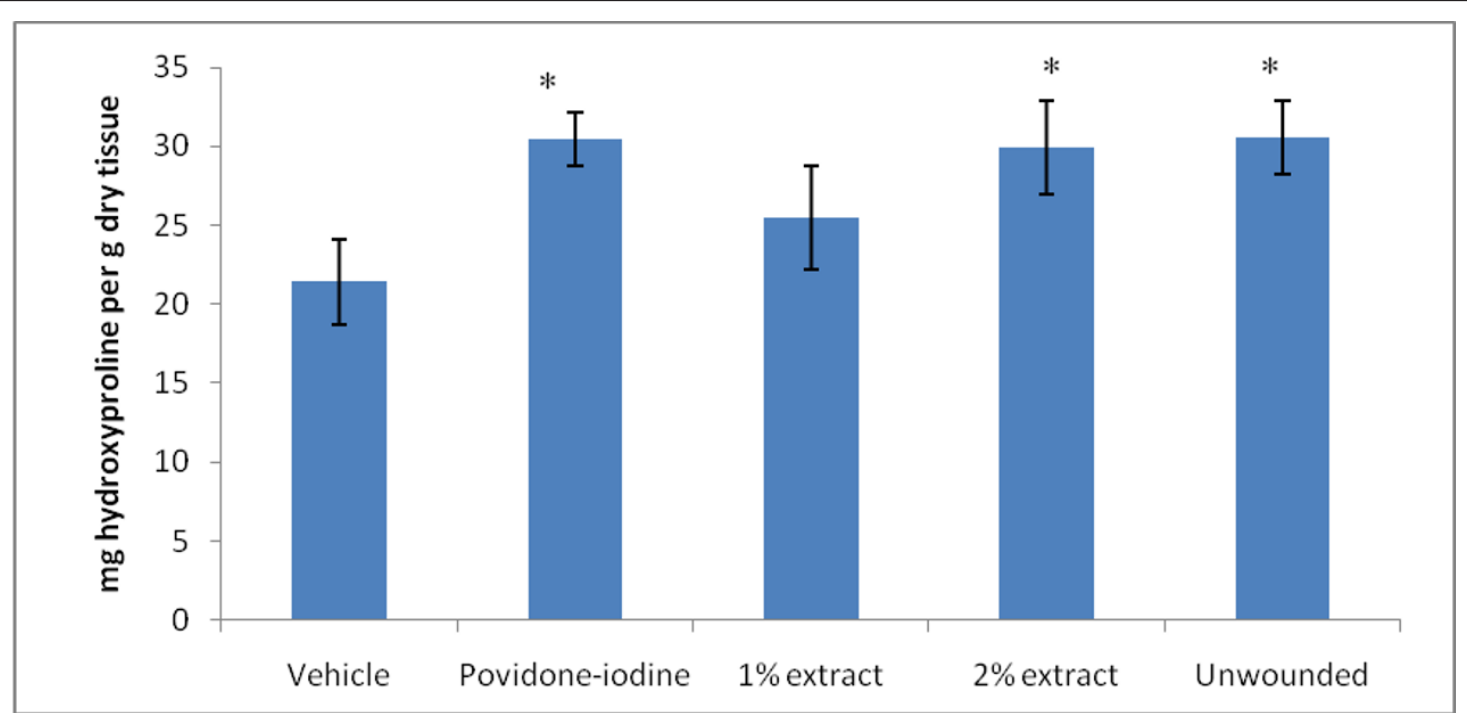

Figure 2 Effect of extracts on in vitro collagen synthesis as measured by hydroxyproline analyses. Data are mean \pm S.D of triplicate measurements from 6 rats. *implies significant difference at $p<0.001$ compared to the vehicle group. 

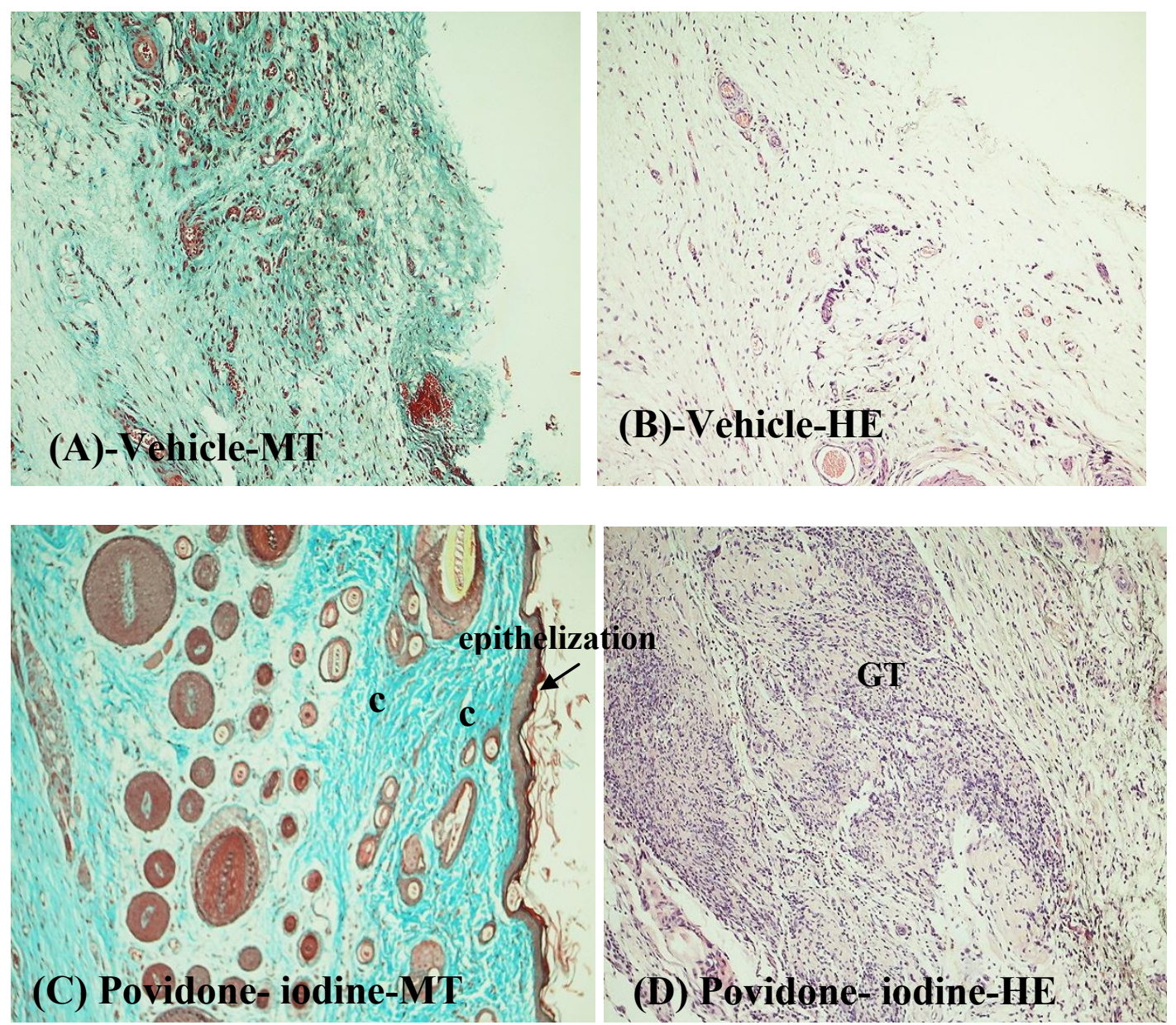

Figure 3 Histological examination of healed wound sections of the vehicle (A and B) and povidone-iodine-treated group (C and D) MT refers to Mason trichrome stained; HE refers to hematoxylin-eosin stained. Magnification: 100X. Abbreviation: C, collagen fibers; GT, granulation tissue; bc, blood capillaries.

Greater tissue regeneration was observed in the povidone-iodine-treated group (Figure 3C and 3D) and the 2\% extract-treated group (Figure 4C and 4D) as demonstrated by the complete epithelization (Figure $3 \mathrm{C}$ and $4 \mathrm{C}$ ), significantly higher collagen deposition (more intense blue coloration in Figure $3 \mathrm{C}$ and $4 \mathrm{C}$ ) and granulation tissues (Figure $3 \mathrm{D}$ and $4 \mathrm{D}$ ) compared to the healed wounds dressed with vehicle (Figure 3A and 3B). Figure 5 shows the histological patterns of the sections stained in H\&E at $400 \times$ magnification. More number of fibroblast cells and newly formed blood capillaries (angiogenesis) were observed with the 2\% extract-treated group (Figure 5D) in comparison to the vehicle group (Figure 5A) and 1\% extract-treated group (Figure 5C). These observations indicated a dose-dependent response in wound healing activity (Figure 5C and 5D).

\section{Discussion}

Our histological findings correlated well with the findings from wound contraction measurement, mean epithelization time study and the biochemical marker test of the hydroxyproline. The significant reduction in wound size and mean epithelization time as well as the higher hydroxyproline content in the $2 \%$ extract-treated group as compared to those from vehicle group corroborates with the histopathological findings of increased epithelization activity, angiogenesis, granulation tissue formation and higher collagen fibers formation (Figures 3, 4, 5 and Table 3). These findings imply that the tannins present in the water extract of $B$. orientale promoted wound healing activity by acting at the proliferative stage via angiogenesis, collagen deposition, granulation tissue formation, epithelization and wound contraction.

Polyphenolic flavonoids and tannins are reported to facilitate wound healing [11]. The wound healing potential of the water extracts of $B$. orientale is a result of the mixture of these phyto-constituents as substantial amounts of these have been found in our earlier study 

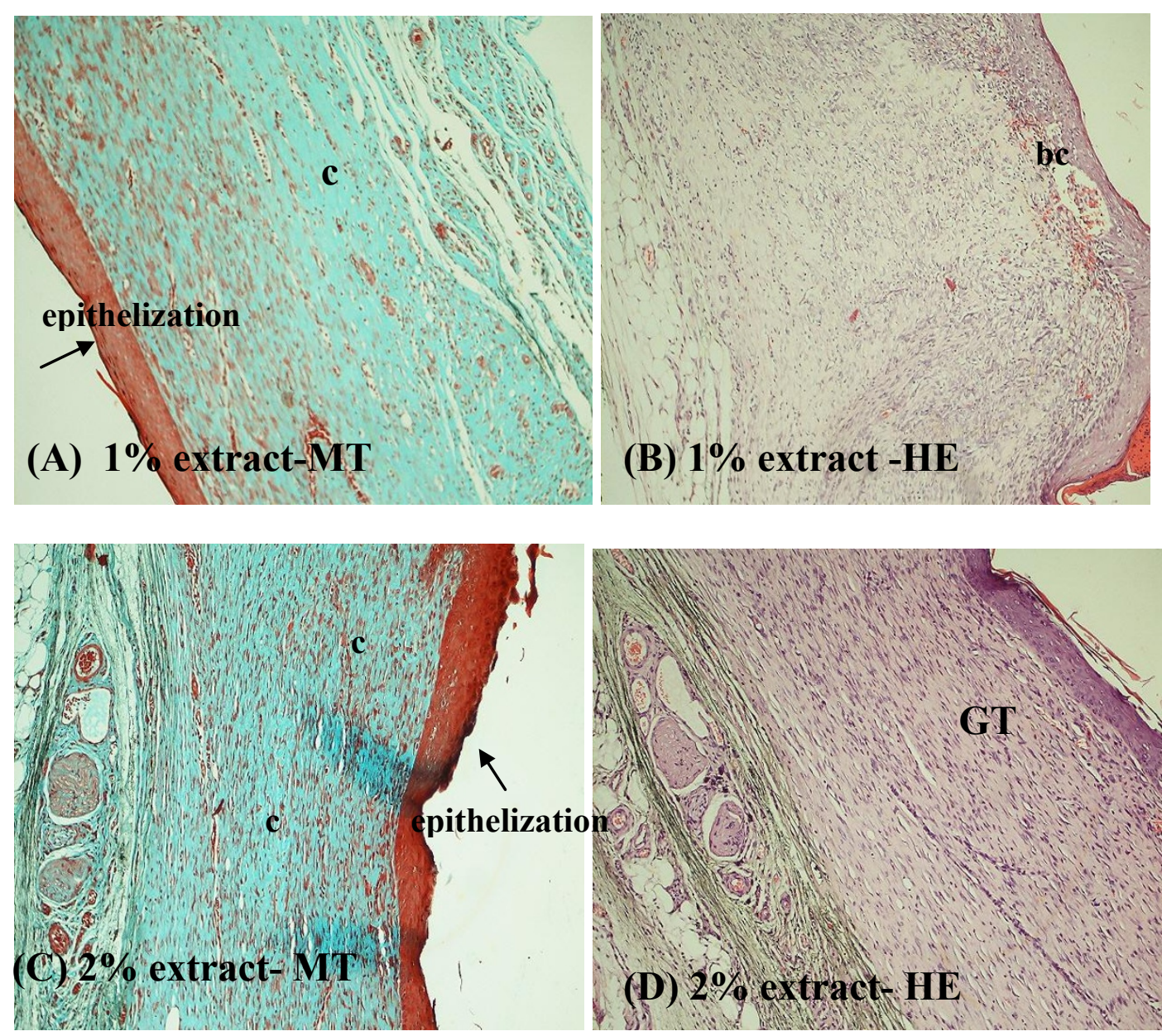

Figure 4 Histological examination of healed wound sections of $1 \%$ extract-treated group (A and B) and $2 \%$ extracted treated group ( $C$ and D). MT refers to Mason trichrome stained; HE refers to hematoxylin-eosin stained. Magnification: 100X. Abbreviation: $\mathrm{C}$, collagen fibers; GT, granulation tissue; bc, blood capillaries.

[7]. Tannins promote wound healing through several cellular mechanisms: scavenging of free radicals and reactive oxygen species, promoting contraction of the wound and increasing the formation of capillary vessels and fibroblasts [22]. A quantitative analysis on the tannin content of the water extract revealed $20 \pm 4 \%$ tannins (measured as g tannic acid equivalent/100 $\mathrm{g}$ extract). Similar findings have been reported with extracts of plants containing 20-40\% tannins [22,23]. The astringent and antimicrobial properties of tannins are important attributes to the wound healing properties [22].

Our earlier studies have revealed strong antioxidant activity (comparable to $\alpha$-tocopherol) and bactericidal activity against methicillin-resistant Staphylococcus aureus (MRSA), Staphylococcus aureus, Micrococcus luteus, Bacillus cereus and Staphylococcus epidermidis [7]. The ability to scavenge free radicals and exert bactericidal effect is known to play an important role in the treatment of wounds at the proliferative stage. Reactive oxygen species can induce severe tissue damage and even lead to neoplastic transformation decreasing the healing process by damages in cellular membranes, DNA, proteins and lipids [24]. Skin pathogens such as $S$. aureus, S. epidermidis and M. luteus are also important contributing factors for skin infections leading to inflammation and causing delay in wound healing processes. For example, curcumin isolated from Curcuma longa Linn. is reported to have both anti-inflammatory and wound healing activity through its antioxidant property [25], while manuka honey contributes to wound healing through its bactericidal activity against a host of skin pathogens including MRSA [26,27]. Hence, since the water extract possessed both antioxidant and antibacterial activities, the conjoint effects on wound healing processes render it a promising candidate for the treatment of wounds and this also justified its traditional usage in wound treatment. 

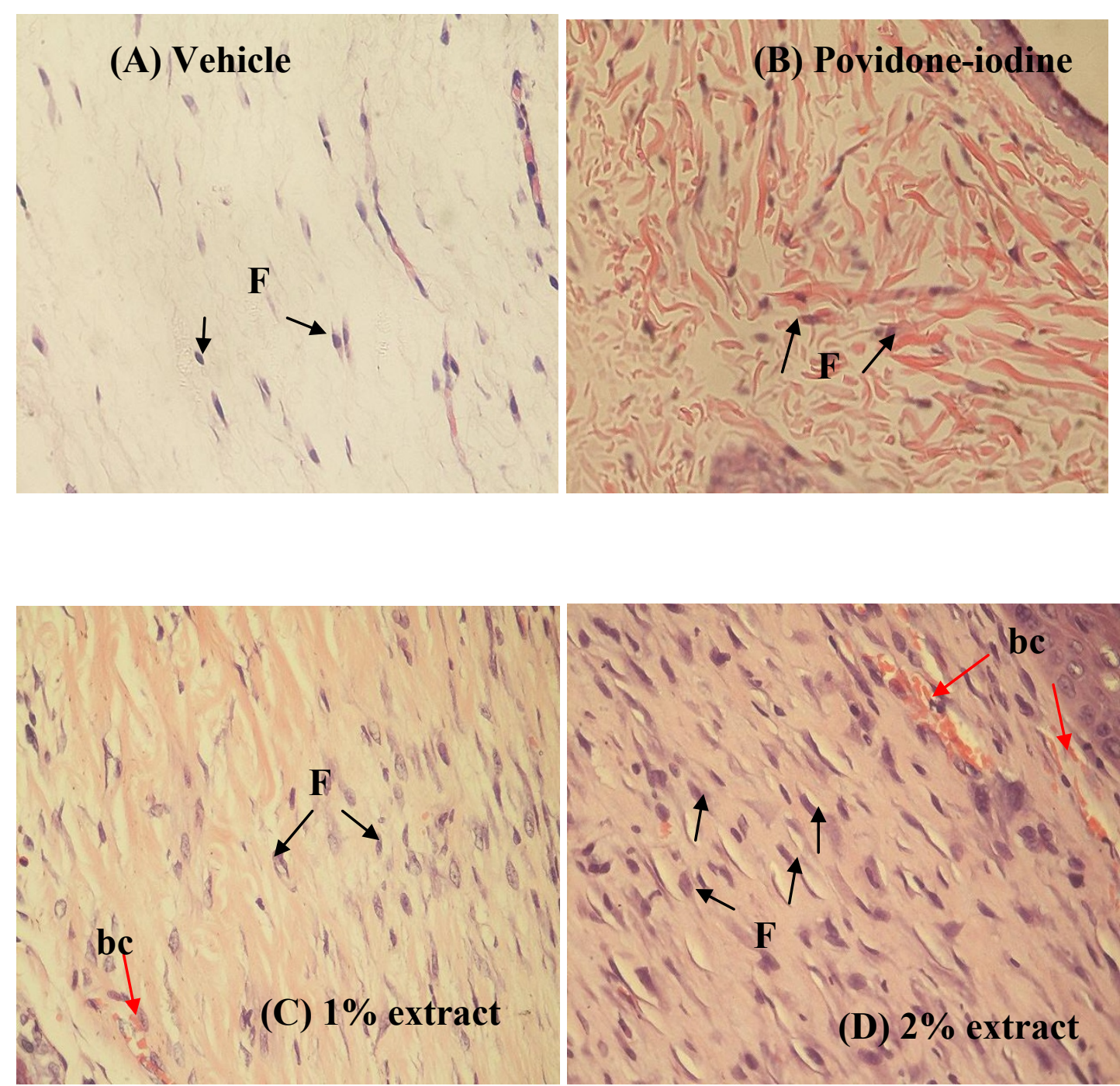

Figure 5 Histological examination of healed wound sections stained with hematoxylin-eosin (HE, 400x magnification). Abbreviation: bc, blood capillaries; F, fibroblast. Black arrow points to fibroblast cells; red arrow points to bc.

\section{Conclusions}

The results revealed a potential for the water extract of $B$. orientale to be used as an external application for the treatment of wounds. The water extract cream in $2 \%$ $(\mathrm{w} / \mathrm{w})$ concentration was capable of producing significant $(\mathrm{p}<0.001)$ wound healing activity. Histopathological findings correlated well with wound contractions, mean epithelisation time study and the biochemical marker test of hydroxyproline. The mechanism of action of the extracts was postulated to

Table 3 Histopathological evaluation of wound healing parameters on healed wounds of the vehicle-, povidoneiodine-, $1 \%$ extract- and $2 \%$ extract-treated animals

\begin{tabular}{ccccc}
\hline Groups & Collagen formation & Fibroblast proliferation & Angiogenesis & Epithelization \\
\hline Vehicle & + & + & ++ \\
Povidone-iodine & +++ & +++ & ++ \\
$1 \%$ extract & ++ & ++ & ++ & ++ \\
$2 \%$ extract & +++ & +++ & ++ & ++ \\
\hline
\end{tabular}

Sections were scored from light $(+)$, moderate $(++)$ or intense $(+++)$ based on relative intensity of the blue coloration in the MT stained sections (for collagen evaluation), the relative density of fibroblast cells and blood capillaries in the H\&E stained sections (for fibroblast proliferation and angiogenesis) and the complete formation of epidermis in the H\&E stained sections (for epithelization). 
be via angiogenesis, collagen deposition, granulation tissue formation, epithelization and wound contraction at the proliferative stage and these actions are attributed to the synergistic effects of the strong antioxidant and antibacterial effect of tannins in the extract.

\section{Acknowledgements}

This study was supported by a research grant from Monash University Sunway Campus. We are grateful to Mr Andrew Leong for his technical assistance and professional advice throughout the study. We also wish to acknowledge the contribution of the fern by the administrators of Putrajaya Botanical Garden, Kuala Lumpur.

\section{Author details}

1School of Biosciences, Taylor's University Lakeside Campus, No. 1, Jalan Taylor's, 47500 Subang Jaya, Selangor, Malaysia. ${ }^{2}$ School of Science, Monash University Sunway Campus, Bandar Sunway, 46150 Petaling Jaya, Selangor, Malaysia. ${ }^{3}$ Department of Physiology, Faculty of Medicine, University of Malaya, 50603 Kuala Lumpur, Malaysia.

\section{Authors' contributions}

HYL carried out the experimentation as part of PhD study and drafted the manuscript. YYL supervised the work, evaluated the data and corrected the manuscript for publication. KHK supervised the work and evaluated the data. All authors read and approved the final manuscript.

\section{Competing interests}

The authors declare that they have no competing interests.

Received: 23 May 2011 Accepted: 12 August 2011

Published: 12 August 2011

\section{References}

1. Ahmad F, Holdsworth DK: Medicinal Plants of Sabah, East Malaysia - Part I. Pharm Biol 2003, 41:340-346.

2. Benjamin A, Manickam VS: Medicinal pteridophytes from the Western Ghats. Indian J Trad Knowl 2007, 6:611-618.

3. Maridass M, Ghantikumar S: Antibacterial activity of leaves of Blechnum Orientale L. Pharmacologyonline Newsletter 2008, 3:58-60.

4. Nick A, Rali T, Sticher O: Biological screening of traditional medicinal plants from Papua New Guinea. J Ethnopharmacol 1995, 49:147-156.

5. Piggott AG: Ferns of Malaysia in colour. Tropical Press, Kuala Lumpur; 1996, 400-401.

6. Sharief MU, Rao RR: Ethnobotanical studies of Shompens - A critically endangered and degenerating ethnic community in Great Nicobar Island. Curr Sci 2007, 93:1623-1628.

7. Lai HY, Lim YY, Kim KH: Blechnum Orientale Linn - a fern with potential as antioxidant anticancer and antibacterial agent. BMC Complement Altern Med 2010, 10:15

8. Lai HY, Lim YY, Tan SP: Antioxidative, tyrosinase inhibiting and antibacterial activities of leaf extracts from medicinal ferns. BiosC Biotechnol Biochem 2009, 73:1362-1366.

9. Myers KA, Marshal RD, Friedin J: Principles of Pathology in Surgery Blackwell Scientific Publications, London; 1 1980, 58-82.

10. Raina R, Parwez S, Verma PK, Pankaj NK: Medicinal plants and their role in wound healing. Online Veterinary J 2008, 3:21.

11. Prabu D, Nappinai M, Ponnudurai K, Prabhu K: Evaluation of woundhealing potential of Pisonia grandis R. Br: A preclinical study in Wistar rats. Int J Low Extrem Wounds 2008, 7:21.

12. Fu XB, Fang LJ, Li HH, Li XK, Cheng B, Sheng ZY: Adipose tissue extract enhances skin wound healing. Wound Repair Regen 2007, 15:540-548.

13. Nayak BS, Sandiford S, Maxwell A: Evaluation of the wound-healing activity of ethanolic extract of Morinda citrifolia L. leaf. Evid based Complement Alternat Med 2009, 6:351-356.

14. Jorge MP, Madjarof C, Ruiz ALTG, Fernandes AT, Rodrigues RAF, Sousa IMO, Foglio MA, de Carvalho JE: Evaluation of wound healing properties of Arrabidaea chica Verlot extract. J Ethnopharmacol 2008, 118:361-366.
15. Akkol EK, Koca U, Pesin I, Yilmazer D, Toker G, Yesilada E: Exploring the wound healing activity of Arnebia densiflora (Nordm.) Ledeb. by in vivo models. J Ethnopharmacol 2009, 124:137-141.

16. Makkar HPS, Siddhuraju P, Becker K: Tannins. Plant secondary metabolites Humana Press, Inc. Totowa, New Jersey; 2007, 67-82.

17. Beaver BV, Reed W, Leary S, McKiernan B, Bain F, Schultz R, Bennet BT Pascoe P, Shull E, Cork LC, Francis-Loyd R, Amass KD, Johnson R, Schmidt RH, Underwood W, Thornton GW, Kohn B: 2000 Report of the AVMA panel on euthanasia. J Am Vet Med Assoc 2001, 218:669-696.

18. Kaur GJ, Arora DS: Antibacterial and phytochemical screening of Anethum graveolens, Foeniculum vulgare and Trachyspermum ammi. BMC Complement Altern Med 2009, 9:30.

19. Reddy BS, Reddy RKK, Naidu VGM, Madhusudhana K, Agwane SB, Ramakrishna S, Diwan PV: Evaluation of antimicrobial, antioxidant and wound healing potentials of Holoptelea integrifolia. J Ethnopharmacol 2008, 115:249-256

20. Braiman-Wiksman L, Solomonik I, Spira R, Tennenbaum T: Novel insights into wound healing sequence of events. Toxicol Pathol 2007, 35:767-779.

21. Aramwit $P$, Sangcakul A: The effects of sericin cream on wound healing in rats. Biosci, Biotechnol Biochem 2007, 71:2473-2477.

22. Choudhary GP: Wound healing activity of the ethanol extract of Terminalia bellirica Roxb. fruits. Nat Prod Rad 2008, 7:19-21.

23. Rane MM, Mengi SA: Comparative effect of oral administration and topical application of alcoholic extract of Terminalia arjuna bark on incision and excision wound in rats. Fitoterapia 2003, 74:553-558.

24. Martindale $\mathrm{L}$, Holbrook NJ: Cellular response to oxidative stress: signaling for suicide and survival. J Cellular Physiol 2002, 192:1-15.

25. Biswas TK, Murkherjee B: Plant medicines of Indian origin for wound healing activity: A review. Int J Low Extrem Wounds 2003, 2:25.

26. Cooper R: A review of the evidence for the use of tropical antimicrobial agents in wound care. World wide wounds 2004 [http://www. worldwidewounds.com], accessed on 20 June 2010.

27. Molan PC: The antibacterial activity of honey. Part 1. Its use in modern medicine. Bee World 1992, 80:5-28.

Pre-publication history

The pre-publication history for this paper can be accessed here: http://www.biomedcentral.com/1472-6882/11/62/prepub

doi:10.1186/1472-6882-11-62

Cite this article as: Lai et al:: Potential dermal wound healing agent in Blechnum orientale Linn. BMC Complementary and Alternative Medicine 2011 11:62

\section{Submit your next manuscript to BioMed Central and take full advantage of:}

- Convenient online submission

- Thorough peer review

- No space constraints or color figure charges

- Immediate publication on acceptance

- Inclusion in PubMed, CAS, Scopus and Google Scholar

- Research which is freely available for redistribution
C Biomed Central 